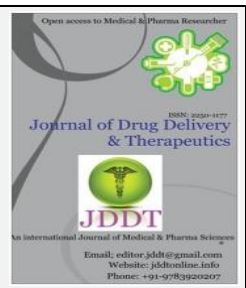

Open Access

Research Article

\title{
Enhancement of solubility of Metaclopramide using solid dispersion technique with different carriers (HPßCD, PVP K-30)
}

\author{
Moumita Paul 1, Pintu Sarkar2, Riyanka Sengupta ${ }^{3}$, Saikat Bhunia ${ }^{4}$, Payal Jana ${ }^{5}$, Chandan Kumar6, Goutam \\ Mukhopadhyay ${ }^{7 *}$
}

${ }^{1}$ Guru Nanak Institute of Pharmaceutical Science and Technology.Kolkata-700114, West Bengal, India.

2,3,4,5,7 BCDA College of Pharmacy and Technology, 78 Jessore Road, Hridaypur, Kolkata-700127, India

${ }^{6}$ Calcutta Institute of Pharmaceutical technology \& Allied .health science, Banitabla, Uluberia, Howrah-711316, India.

\begin{abstract}
Modern drug discovery has led to the development of drug molecules that exhibit high lipophilicity and poor water solubility, which leads to problematic bioavailability. Approaches have thus been made to enhance dissolution of poorly water soluble drugs through modifications and creation of specific formulations. Metaclopramide is an antiemetic and gastroprokinetic agent, commonly used to treat nausea and vomiting. It is absorbed well after oral administration but a significant first pass effect in some human patients may reduce systemic bioavailability to $30 \%$.The Metaclopramide base is thus modified from Metaclopramide hydrochloride to enhance solubility .This has been achieved by the formulating in solid dispersion since Metaclopramide is poorly water soluble. Though it is absorbed well after oral administr ation, a significant first pass effect in some patients reduces systemic bioavailability, which can cause adverse side effects. This solid dispersion has then been used through transdermal drug delivery. Enhancement of solubility of poorly water soluble drug by solid dispersion may be attributed to particles modified characters such as particle size reduction, improved wettability, higher porosity, decreased lattice energy, amorphous state. The main objective thus includes modification of drug Metaclopramide hydrochloride to Metaclopramide base, preparation of solid dispersion of modified Metaclopramide base drug which has poor water solubility, experimental analysis of Metaclopramide base drug and solid dispersion products with carriers.
\end{abstract}

Keywords: solubility, Metaclopramide, solid dispersion, carriers, HP $\beta C D$, PVP K-30

Article Info: Received 04 Sep 2019; $\quad$ Review Completed 13 Oct 2019; $\quad$ Accepted 16 Oct 2019; Available online 15 Nov 2019

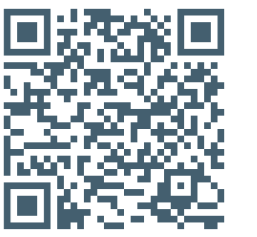

\section{Cite this article as:}

Paul M, Sarkar P, Sengupta R, Bhunia S, Jana P, Kumar C , Mukhopadhyay G, Enhancement of solubility of Metaclopramide using solid dispersion technique with different carriers (HP $\beta C D$, PVP K-30), Journal of Drug Delivery and Therapeutics. 2019; 9(6):17-22 http://dx.doi.org/10.22270/jddt.v9i6.3652

Dr. Goutam Mukhopadhyay, BCDA College of Pharmacy and technology, 78 Jessore Road, Hridaypur, Kolkata-700127, India

\section{INTRODUCTION:}

Metaclopramide is chemically 4-amino-5-chloro-N-[2(diethyl amino)ethyl]-2methoxybenzamide..The antiemetic action of Metaclopramide is due to its antagonist activity at D2 receptors in the chemoreceptor trigger one in the central nervous system and this action prevents nausea and vomiting triggered by most stimuli. The gastroprokinetic activity is mediated by muscarinic activity, D2 receptor antagonist activity and 5 HT-4 receptor agonist activities. It has a molecular weight of 299.8 and its melting point is 147 degree Celsius.

Enhancement of solubility of poorly water soluble drug can be done by solid dispersion technique. ${ }^{1,2,3,4}$ Though there are simple techniques to prepare solid dispersions problems are often encountered , such as physicochemical stability of drug and vehicle, making suitable formulation of solid dispersion of into dosage forms and scale up of process.<smiles>CCN(CC)CCNC(=O)c1cc(Cl)c(N)cc1OC</smiles>

Fig-1:-Structure of Metaclopramide

R. Vijaya et, al (2012) expressed 5 that transdermal drug delivery delivers the drug through topical route for systemic effect at a predetermined and controlled rate. In this study, transdermal films of amitriptyline $\mathrm{HCl}$ has been formulated using polymers of hydroxypropyl cellulose and polyvinyl 
pyrolidone in different compositions, the films were then evaluated for their physicochemical properties.

Complexation is one such technique of preparing a solid dispersion, wherein the drug is bound to a carrier because of weak Vander waals forces and it is released from its bound state only when it gets exposed to a suitable chemical environment. In this kind of solid mixture a guest molecule forms complex with an inert soluble carrier (host molecule) in the solid state. One of the most widely used complex carriers is within the class of cyclodextrins $6,7,8$ Cyclodextrins are a family of cyclic oligosaccharides composed of $\alpha$ $(1,4)$ linked glucopyranose subunits. It is composed of interior hydrophobic cavity, whereas the exterior is highly hydrophilic. The lipophilic cavity of cyclodextrin molecules provides a microenvironment into which appropriately sized non polar moieties can enter to form inclusion complex. ${ }^{9}$ Complex formation between cyclodextrin and a substrate is assessed by its binding/stability constant.

Yvaraja et al,in (2014) ${ }^{10}$ prepared solid dispersion of carvedilol for enhancement of aqueous solubility. To increase solubility polymers like Beta Cyclodextrin, Hydroxypropyl-beta-cyclodextrin were used. The following solid dispersion were then evaluated through phase solubility studies, determination of partition coefficient, drug content (\%) and in vitro dissolution studies.

Domanska et al in 2011,investigated ${ }^{11}$ the guest host complex formation of three drug derivatives of anthranilic acid,mefenamic acid, niflumic acid with 2-hydroxypropyl- $\beta$ cyclodextrin in aqueous solutions. It was found that solubility of sparingly soluble drugs has been improved by the addition of 2-hydroxypropyl- $\beta$-cyclodextrin at two temperatures $298.15 \mathrm{~K}$ and $310.15 \mathrm{~K}$ and two $\mathrm{pH}$ values 2 and 7 .
The outer surface of the cone is
hydrophilic and the center cavity hydrophilic and
is hydrophobic
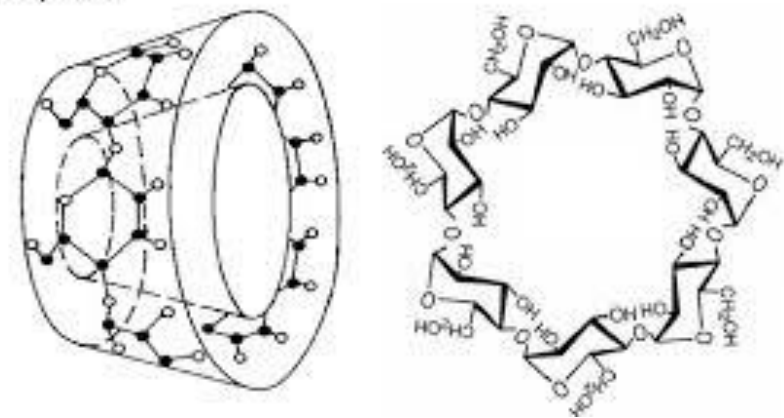

Fig 2:-Structure of Cyclodextrin molecule

\section{The Biopharmaceutics classification system:}

It is a system to differentiate drugs on the basis of their solubility and permeability. It is a guide for predicting the intestinal drug absorption provided by the U.S Food and Drug Administration.

According to the Biopharmaceutics 12,13,14,15 Classification System, drug substances are classified as follows:

1. Class I-high permeability, high solubility: Those compounds are well absorbed and their absorption rate is usually higher than excretion.

2. Class II-high permeability, low solubility: The bioavailability of those products is limited by their solvation rate.

3. Class III-low permeability, high solubility: The absorption is limited by the permeation rate but the drug is solvated very fast. If the formulation does not change the permeability or gastro-intestinal duration time, then Class I criteria can be applied.

4. Class I-high permeability, high solubility: Those compounds have a poor bioavailability. Usually they are not well absorbed over the intestinal mucosa and a high variability is expected.

\section{MATERIALS AND METHODS USED:}

\section{Polymers used:}

1. Hydroxypropyl- $\beta$-cyclodextrin(HP $\beta C D)$.(Tokyo Chemical Industries Co. Ltd)

Table 1-Physicochemical properties of HP $\beta C D$

\begin{tabular}{|l|l|}
\hline Appearance & White crystalline powder \\
\hline Solubility in water at $25^{\circ} \mathrm{C}$ & $50 \mathrm{~g} /$ lit \\
\hline Melting point & $278^{\circ} \mathrm{C}$ \\
\hline Degree of substitution & $4-6$ \\
\hline
\end{tabular}

2. Polyvinyl pyrolidone (PVP K-30).(Loba Chemi, Mumbai)

\begin{tabular}{|l|l|}
\hline Solubility & $\begin{array}{l}\text { Soluble in water, chloroform, alcohol, } \\
\text { chlorinated hydrocarbons }\end{array}$ \\
\hline Melting point & $150-180^{\circ} \mathrm{C}$ \\
\hline Appearance & $\begin{array}{l}\text { White to light yellow, hygroscopic, } \\
\text { amorphous powder }\end{array}$ \\
\hline Density & $1.2 \mathrm{~g} / \mathrm{cm}^{3}$ \\
\hline
\end{tabular}

Table 2-Physicochemical properties of PVP-K30

\section{Drug used:}

Metaclopramide $\mathrm{HCl}($ Yarrow Chemical)

\section{Reagents used:}

Potassium dihydrogen phosphate (Merck Specialities Pvt Ltd.), Sodium hydroxide (Merck Specialities Pvt Ltd.), sodium chloride(Qualichems Pvt Ltd New Delhi)

Solvents used: acetone (Quest Chemicals, Kolkata) , methanol (Spectrochem Pvt Ltd. Mumbai), ethanol(obtained from departmental store of Pharm Tech. Jadavpur University), Double distilled water(obtained from lab of Pharmaceutical Engineering, Pharm Tech dept. Jadavpur Univ.)

Instruments: UV Visible Spectrophotometer (ANALAB, UV 180), Water bath (Integrated electrolife system by SUNBIM), Magnetic stirrer(Trasons,multispins)

\section{Conversion of Metaclopramide hydrochloride to Metaclopramide base form:}

Metaclopramide base form is required which is usually available in its hydrochloride form. Required amount of Metaclopramide hydrochloride was dispersed in sufficient double distilled water followed by stirring until the total amount of drug gets fully dissolved. The solution was neutralized by $1 \mathrm{M}$ sodium hydroxide solution and gradually a precipitate was formed. The precipitate was collected by filtration and the precipitate thus obtained was washed several times with double distilled water to remove $\mathrm{HCl}$ which was produced during precipitation. The wet precipitate was dried in hot air oven at 50 degrees Celsius. Afterwards the solid material was cooled up to room temperature (25 degrees Celsius).Next; dried solid material 
was treated with acetone to make a saturated solution ad stirred continuously at 50 degree Celsius. The solution was allowed to attain room temperature and thereafter it was kept in a refrigerator and crystal particles of Metaclopramide (base form) was formed and collected and dried in 50 degrees Celsius in hot air oven. The material was cooled at room temperature and it was weighed.

\section{Determination of aqueous solubility of drug:}

Aqueous solubility study was performed by taking excess amount of Metaclopramide in an aqueous phase (phosphate buffer $\mathrm{pH} 7.4$, double distilled water, phosphate buffer $\mathrm{pH}$ 6.8 and pH 5.5 buffer) and shaken at $37^{\circ} \mathrm{C}, 40^{\circ} \mathrm{C}, 45^{\circ} \mathrm{C}$. After 24 hours absorbance was observed to obtain solubility.

\section{Phase solubility study:}

Phase solubility was carried out by dissolving known amount of polymers with increasing amount to each of series of test tubes containing aqueous phase (phosphate buffer $\mathrm{pH}$ 7.4, double distilled water).Thereafter excess amount of drug was added to each of the tube and shaken for 24 hour at $25^{\circ} \mathrm{C}, 37^{\circ} \mathrm{C}, 40{ }^{\circ} \mathrm{C}, 45^{\circ} \mathrm{C}$ respectively. After 24 hour, very slight quantity of insoluble material(drug) was observed at the bottom of each test tube and then content of each test tube was filtered and filtrate was collected and its absorbance recorded. Phase solubility curve was constructed and thermodynamic and binding constants were calculated.

\section{Preparation of Metaclopramide Solid dispersion:}

Solvent evaporation technique was carried out by dispersing physical mixture and polymer at certain common ratio and then it was evaporated until transparent solvent free thin layer of mass was obtained. Then the film was dried till constant weight at 50 degrees Celsius.

2.6 Characterization of Metaclopramide solid dispersion:

Characterization of solid dispersion was performed by instrumental analysis 16,17 like Fourier Transform Infrared Spectroscopy (FTIR) analysis and Differential Scanning Calorimetry (DSC) analysis . FTIR analysis was done to observe the stability of drug 18,19 and also to confirm drug polymer interaction if any. DSC analysis was carried out for Metaclopramide loaded solid dispersions, physical mixture and also for pure drug to analyze the crystallinity and amorphous nature of compounds.

\section{RESULTS AND DISCUSSION:}

$\lambda_{\max }$ of Metaclopramide base determined first by scanning solution of Metaclopramide in UV Spectrophotometer. $\lambda_{\max }$ was found to be $272 \mathrm{~nm}$

Preparation of calibration curve: The standard curves was prepared by plotting absorbance against concentration of individual analysts.

Table 3: absorbance of Metaclopramide at $272 \mathrm{~nm}$ for different concentrations in DDW, pH 5.5

\begin{tabular}{|c|c|c|c|}
\hline Serial no: & Concentration $(\boldsymbol{\mu g} / \mathbf{m L})$ & $\begin{array}{l}\text { Absorbance at 272 } \mathbf{~ n m} \text { in } \\
\text { diff conc. DDW }\end{array}$ & $\begin{array}{l}\text { Absorbance at 272 nm in } \\
\text { diff conc. } \mathbf{p H ~ 5 . 5}\end{array}$ \\
\hline 1 & 2 & 0.113 & 0.1018 \\
\hline 2 & 4 & 0.2112 & 0.1972 \\
\hline 3 & 6 & 0.3056 & 0.2844 \\
\hline 4 & 8 & 0.411 & 0.3866 \\
\hline 5 & 10 & 0.5112 & 0.4752 \\
\hline 6 & 12 & 0.615 & 0.5826 \\
\hline
\end{tabular}

The calibration graph was found linear in range of of 2 to $12 \mathrm{~g} / \mathrm{mL}$ in Double distilled water,pH 5.5

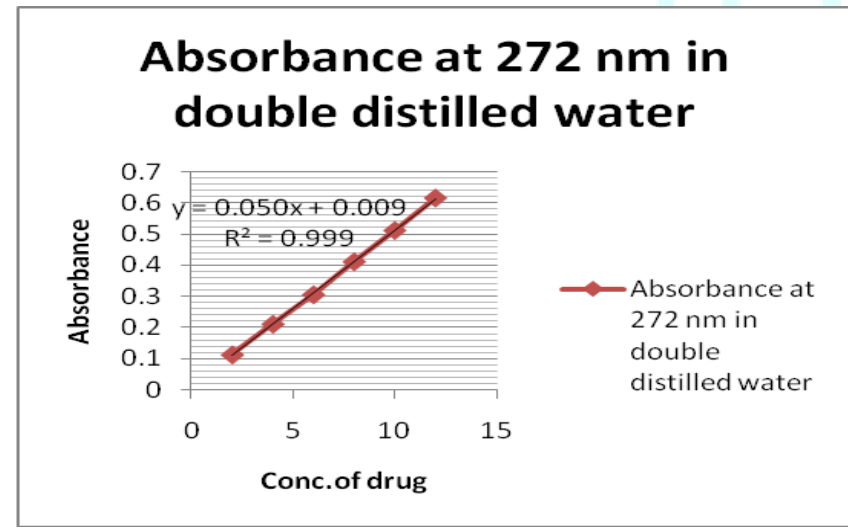

Fig 3: Standard curve in DDW

The phase solubility study is carried out to determine binding/complexation of polymer-drug complexes. These complexes effectively modify solubility characteristics of drug. Phase solubility studies of binary systems (METHP $\beta C D$, MET-PVP K-30)were performed to see effects of complexation ability of different carrier systems. The shapes of phase solubility profiles were found to be $A_{L}$ type isotherms for PVP K-30 and HP $\beta C D$. $A_{L}$ type linear profile suggests solubility enhancement of a guest molecule as a

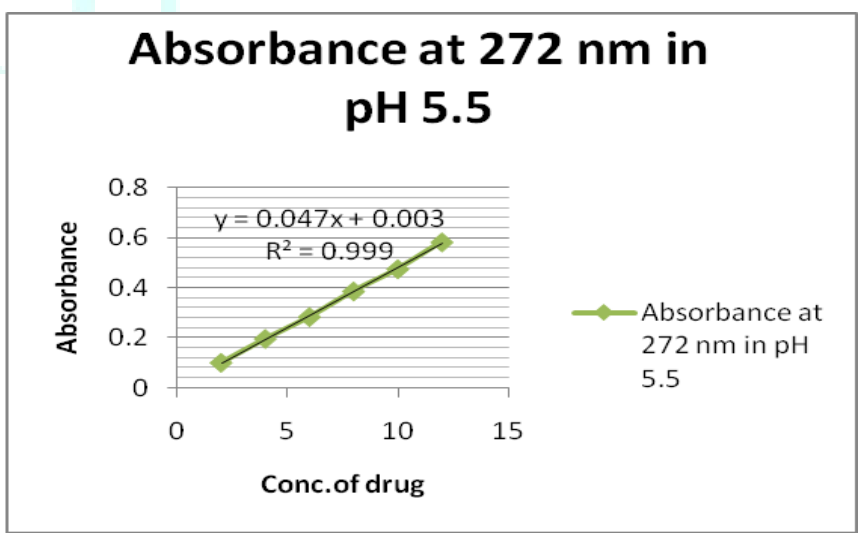

Fig 4: Standard curve in $\mathrm{pH} 5.5$

function of carrier's concentration. The profiles showed different values of intercept and slope as temperature and $\mathrm{pH}$ of media were varied. Stability constant was calculated by intercept and slope of linear part of profile. The apparent complexation constants $\left(\mathrm{K}_{\mathrm{c}}\right)$ and thermodynamic parameters( $\Delta \mathrm{G}, \Delta \mathrm{H}, \Delta \mathrm{S}$ ) of the phase solubility studies with three aqueous media(DDW,pH 5.5) at different temperatures(298 K,310 K, $313 \mathrm{~K}, 318 \mathrm{~K})$. 
Table 4: Binding constants and thermodynamic functions for the interactions of Metaclopramide base with various carriers in different $\mathrm{pH}$ mediums in different temperature

\begin{tabular}{|c|c|c|c|c|c|}
\hline Carrier & & Medium, I & & Medium,p & \\
\hline & Temp In K & $\mathrm{K}_{\mathrm{a}}(\mathrm{M}-1)$ & $\Delta \mathrm{G}, \Delta \mathrm{H}, \Delta \mathrm{S}$ & & \\
\hline \multirow{3}{*}{ PVP K-30 } & 298 & 95.71968 & $\begin{array}{l}\Delta \mathrm{G}=-11.3013 \\
\Delta \mathrm{H}=26.60082 \\
\Delta \mathrm{S}=0.127188\end{array}$ & & \\
\hline & 310 & 145.0439 & $\begin{array}{l}\Delta \mathrm{G}=-12.331 \\
\Delta \mathrm{H}=237.4796 \\
\Delta \mathrm{S}=0.83829\end{array}$ & & \\
\hline & 313 & 350.7873 & $\Delta \mathrm{G}=-14.519$ & & \\
\hline \multirow{4}{*}{ HP $\beta C D$} & 298 & 81.57048 & $\begin{array}{l}\Delta \mathrm{G}=-10.905 \\
\Delta \mathrm{H}=-10.3914 \\
\Delta \mathrm{S}=0.001723\end{array}$ & 61.35846 & $\begin{array}{l}\Delta \mathrm{G}=-10.1995 \\
\Delta \mathrm{H}=-19.0854 \\
\Delta \mathrm{S}=-0.02982\end{array}$ \\
\hline & 310 & 69.34625 & $\begin{array}{l}\Delta \mathrm{G}=-10.5027 \\
\Delta \mathrm{H}=-7.88385 \\
\Delta \mathrm{S}=0.008788\end{array}$ & 45.53777 & $\begin{array}{l}\Delta \mathrm{G}=-9.46071 \\
\Delta \mathrm{H}=-9.85321 \\
\Delta \mathrm{S}=-0.00132\end{array}$ \\
\hline & 313 & 67.34263 & $\begin{array}{l}\Delta \mathrm{G}=-10.4301 \\
\Delta \mathrm{H}=-6.46247 \\
\Delta \mathrm{S}=0.013314\end{array}$ & 43.89936 & $\Delta \mathrm{G}=-9.36993$ \\
\hline & 318 & 64.76378 & $\Delta \mathrm{G}=-10.3333$ & 41.68465 & \\
\hline
\end{tabular}

Free energy change for these binary combinations was found negative which indicate spontaneous solubilization .Free energy changes varies from -9 to $-11 \mathrm{~kJ} / \mathrm{mol}$. It suggests that drug may bind with the carrier molecules which are held by weak physical forces like Vander waals forces, hydrogen bonding and some hydrophobic forces.

Effect of temperature on $\mathrm{k}$ in $\mathrm{pH} 5.5$ was much prominent in each binding in comparison with that of DDW. With the rise of temperature mobility of ionic species of MET in acidic $\mathrm{pH}$ increases which in turn possibly inhibits complex formation with the carriers. Complexatio is of exothermic type, entropy changes were found negative in $\mathrm{pH}$ 5.5.Higher $\mathrm{K}$ values for MET-PVP K-30 system was observed in comparison with that of MET-HPCD.MET-PVP K-30 showed low solubility because of influence of high stability constant. If stability constant is too high it may form a more stable complex so drug may not be released out to a greater extent from complexed state.

Table 5: Study of solubility at $37^{\circ} \mathrm{C}$ of binary solid dispersion with carrier HP $\beta C D$

\begin{tabular}{|l|l|l|}
\hline Binary system & $\mathrm{mcg} / \mathrm{mL}$ in DDW & $\mathrm{mcg} / \mathrm{mL}$ in $\mathrm{pH} 5.5$ \\
\hline HP 0:1 & 191.83 & 5553.2 \\
HP 1:1 & 202.04 & 8085.1 \\
HP 2:1 & 353.06 & 14680.8 \\
HP 3:1 & 483.6 & 22340.4 \\
\hline
\end{tabular}

Table 6: Study of solubility at $37^{\circ} \mathrm{C}$ of binary solid dispersion with carrier PVP K-30

\begin{tabular}{|l|l|l|}
\hline Binary system & $\mathrm{mcg} / \mathrm{mL}$ in DDW & $\mathrm{mcg} / \mathrm{ml} \mathrm{in} \mathrm{pH} 5.5$ \\
\hline PVP 0:1 & 191.83 & 5553.2 \\
PVP 1:1 & 383.67 & 10212.7 \\
PVP 2:1 & 489.79 & 15744.7 \\
PVP 3:1 & 602.04 & 21914.9 \\
\hline
\end{tabular}

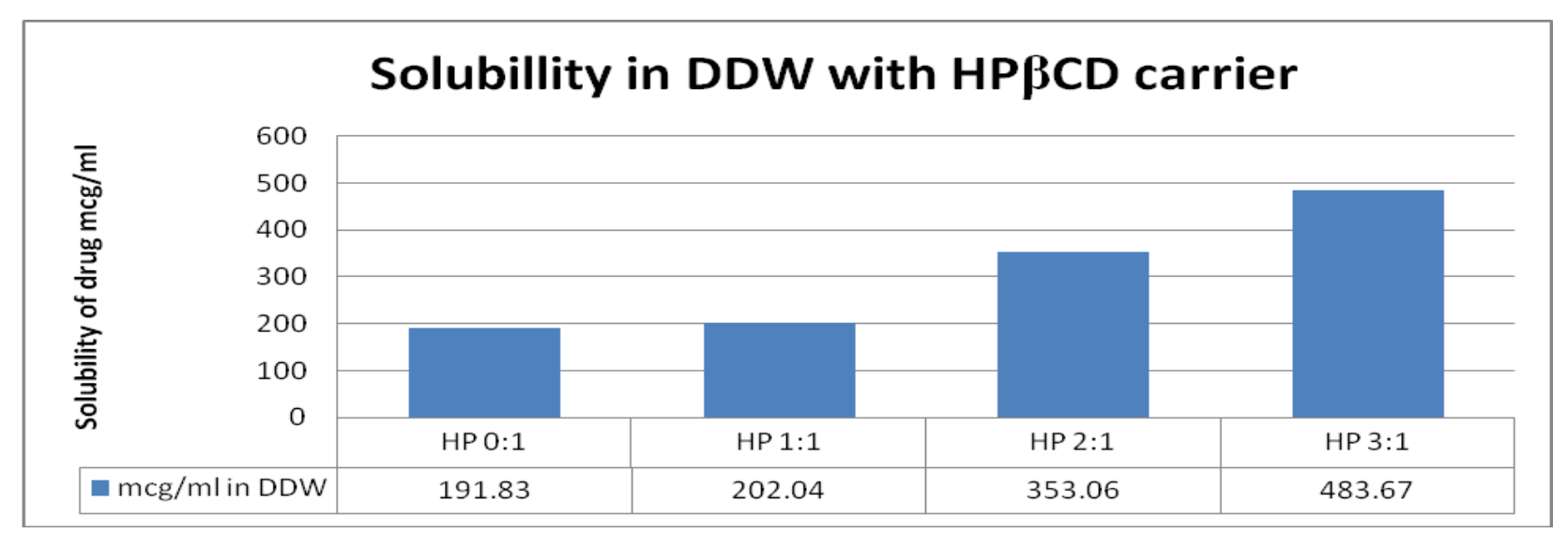

Fig 5: Effect of carrier (HP $\beta C D)$ drug ratio of solid dispersion on solubility of MET in DDW 


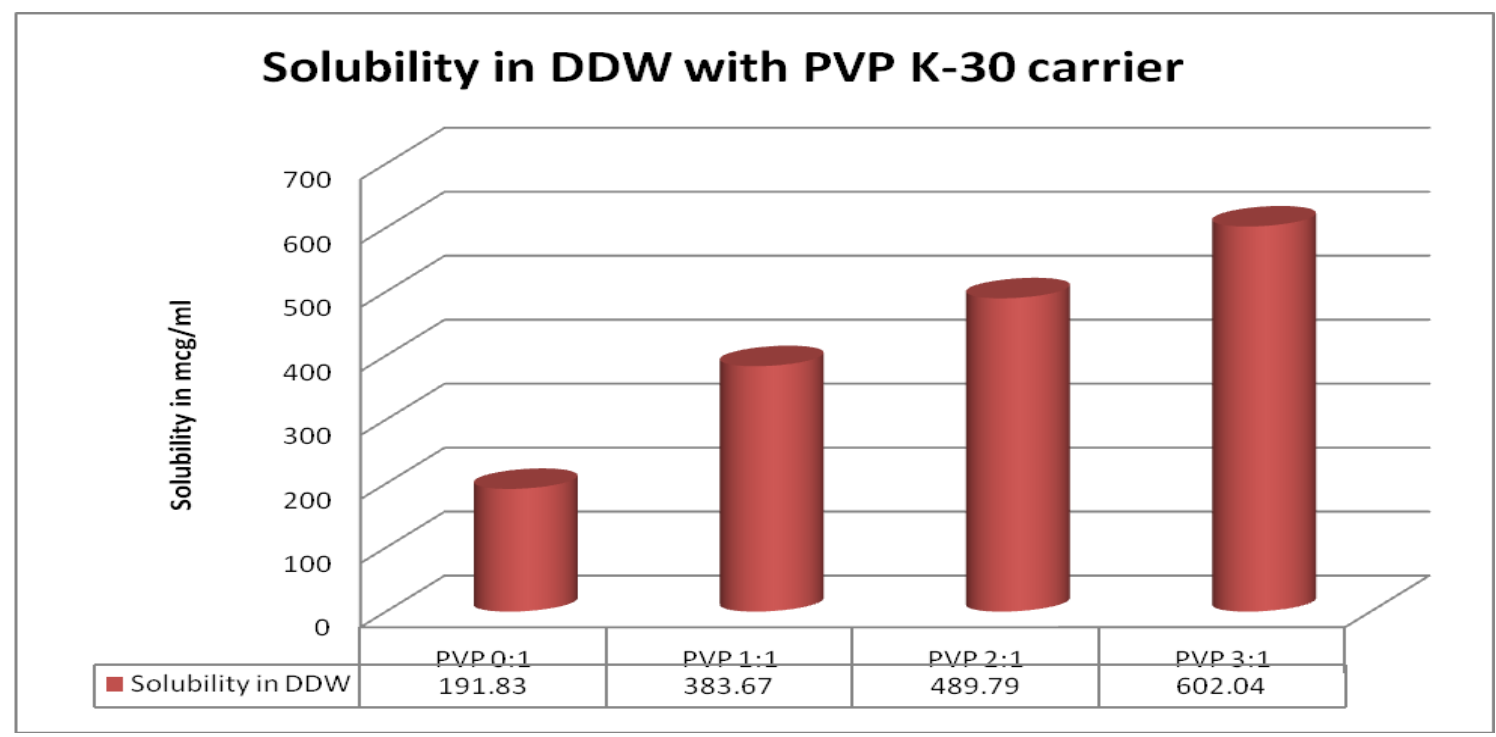

Fig 6: Effect of carrier (PVP K-30) drug ratio of solid dispersion on solubility of MET in DDW

In the following tables saturation solubility of solid dispersions of Metaclopramide prepared with various carriers was shown. Metaclopramide is sparingly soluble in double distilled water(DDW).Its aqueous solubility in Double distilled water increases linearly keeping drug amount fixed when fraction of carrier substance in solid dispersion of drug is increased. As drug amount was fixed (100 mg) its solubility was enhanced up to 5:1 and drug amount was not much higher on further increase of HPßCD .Enhancement of solubility was observed in binary system of carrier drug(3:1) in DDW, approximately 2-3 times.

Solubility in acidic $\mathrm{pH}$ of 5.5 was higher than DDW and it was observed that solubility of drug in pH 5.5 is 28.95 times higher than that of pure drug in DDW samples without any carrier substances.

In case of solid dispersion of PVP K-30, drug solubility enhancement was lesser in comparison with that of HPßCD. Its solubility increases linearly with the increase of amount of carrier in solid dispersion.

\section{CONCLUSION:}

Poor solubility of new chemical entities is a well known problem for the past few decades. Several formulation strategies have been proposed to overcome this. Despite the imbalance between significant research efforts and the few successful marketed formulations the solid dispersion technology still holds a key position among the various formulation strategies to enhance the aqueous solubility/dissolution rate and thereby oral bioavailability of poorly soluble compounds. But only few solid dispersion products are available in market because many others have stability problems. The various processing parameters are involved in the preparation of solid dispersion which influence the effectiveness, usefulness, stability, and safety of the formulation. The use of systemic experimental design along with mathematical optimization is both time and cost efficient and its application assures the formulation quality.

The main objective was to develop modified release dosage form of poorly soluble drugs in an attempt to improve oral bioavailability 20,21 .

\section{REFERENCES:}

1. Bandari S., Jukanti R., Potluri R.H.K. et al: Solubility enhancement and physicochemical characterization of carvedilol solid dispersion with Gelucire 50/13. Archives of Pharmacal Research 2011; 34(1): 51-57.

2. Leuner C., Dressman J . Improving drug solubility for oral delivery using solid dispersion. European J of Pharmaceutics and Biopharmaceutics 2000;50(1): 47-60.

3. Li W., Lan Z., Li M et al:Investigation of structure and dissolution properties of solid dispersion of lansoprazole in polyvinylpyrrolidone. J Of Molecular Structure 2011;1005(1):70-77.

4. Mahale A.M., Sreenivas S. A. Enhancement of Dissolution Profile of Nifedifipine by Solid dispersion Technique. IJPI J of Pharmaceutics and Cosmetology 2011;6(1): 1-8.

5. Vijay R,Manjunath M.N , Umamaheswari S:Formulation and Evaluation of transdermal films of anti depressant drug Amitriptyline hydrochloride using Eudragit E100,HPC and PVP polymer. Int J of Pharmacy and Pharmaceutical Sciences 2012; 4(2): 639-643.

6. J.J.T Labandeira, M.T Diaz, J.L Jato: Inclusion complexation of glibenclamide with 2-hydroxypropyl- $\beta$-cyclodextrin in solution and in solid state. European J of Pharmaceutical Sciences 1994;1(6): 291-296.

7. J.J.T Labandeira, Lopez M.E,Seijo L.C et al: Complexation of the interferon inducer broprimine with hydroxypropyl- $\beta$ cyclodextrin. . European J of Pharmaceutical Sciences 2000; 9(4): 381-386.

8. Loftsson T, Brewster M.E: Pharmaceutical applications of Cyclodextrin.1.Drug solubilization and stabilization. J of Pharmaceutical Sciences 1995;85(10): 1017-1025.

9. Bayomi M. A., Abanumay K. A., Angary A. A. A:Effect of inclusion complexation with cyclodextrins on photostability of nifedipine in solid state. Int J Of Pharmaceutics 2002; 243(1-2);:107-117.

10. K.Yuvaraja, Jasmina Khanam :Enhancement of carvedilol solubility by solid dispersion technique using cyclodextrins, water soluble polymers and hydroxyl acid. J of Pharmaceutical and Biomedical analysis 2012; 96: 10-20.

11. U.Domanska, A.Pelczarska, A.Pobudkowska:Effect of 2-Hydroxy$\beta$-cyclodextrin on Solubility of Sparingly Soluble Drug derivatives of Anthranilic acid .Int J Of Molecular Sciences.2011; 12(4) : 2383-2394.

12.J. Ali, R.K Khar, A. Ahuja: A textbook of Biopharmaceutics and Pharmacokinetics, $2^{\text {nd }}$ edition. Birla Publications: India; 2004.

13. Amidon G.L, Lennernas H, Sh The Biopharmaceutics Classification System h VP et al: A theoretical basis for a pharmaceutical drug classification: the correlation of in vitro 
drug product dissolution and in vivo bioavailability. The AAPS J 2014; 16(5): 894-898.

14. Aggelos C., Maria S., Christel B. et al: The Biopharmaceutics Classification System(BCS) and the Biopharmaceutics Drug Disposition Classification System: Beyond guidelines. Int J Of Pharmaceutics 2019; 566(2):264-281.

15. Ajay Kumar S., Ram S.B, Suresh K.D., et al: Biopharmaceutical Classification System:Tool based prediction for drug dosage formulation. Advance Pharmaeutical J 2017; 2(6):204-209.

16. Li M, Ronaud O, Poncelet D: Microencapsulation by solvent evaporation: State of the art for process engineering approaches. International Journal Of Pharmaceutics 2008; 363(1-2): 26-39

17. Levin M. Pharmaceutical Process Scale Up. $3^{\text {rd }}$ edition. Informa UK Limited. United Kingdom. 2011.
18. Michael E. A., Kevin M.G. Taylor. Aulton's Pharmaceutics,The design and manufacture of medicines, $4^{\text {th }}$ edition. Churchill Livingstone. United Kingdom, 2013.

19. Patrick J.Sinko. Martin's Physical Pharmacy and Pharmaceutical Science, 6th edition. Wolters Kluwer. India, 2010.

20. Brodin B ,Steffansen B, Nielsen U C.: Passive diffusion of drug substances: the concept of flux and permeability.Molecular Biopharmaceutics.

21. Sadozai K.S., Rahman U., Ullah F. et al: Comparative study of domperidone sustained releasematrix tablets prepared by wet granulation and solvent evaporation techniques using xanthan gum. Middle East Journal of Scientific Research 2013; 15(9):1206-1214. 